\title{
Musculoskeletal Injuries in British Army Recruits: A Retrospec- tive Study of Incidence and Training Outcome in Different In- fantry Regiments
}

\author{
Heagerty $\mathrm{RDH}^{1 \#}$, Sharma $\mathrm{J}^{1-3 \#^{*}}$ and Clayton $\mathrm{J}^{1}$ \\ ${ }^{1}$ Rehabilitation Department, Defence Primary Healthcare, Infantry Training Centre, UK \\ ${ }^{2}$ School of Health and Social Care, Teesside University, UK \\ ${ }^{3} 251$ Medical Squadron 3 Medical Regiment, UK
}

${ }^{\#}$ Equally contributed and joint first authors

*Corresponding author: Dr. Jagannath Sharma, PhD, MCSP, RAMC, Rehabilitation Department, Defence Primary Healthcare, Primary Care Rehabilitation Facility, Infantry Training Centre Catterick Garrison, UK, Tel: $+441748872619,+447828079402$, E-mail: Jagannath.sharma706@mod.uk,Jagannath.sharma13@gmail.com

\begin{abstract}
Background: Musculoskeletal Injuries (MSKI) and the subsequent attrition incurred during basic military training represent a significant socioeconomic burden across global defence forces. The collection of accurate injury surveillance data is fundamental to meaningful analysis, identification of trends and subsequent introduction of targeted prevention strategies.

Aim: The purpose of this study was to evaluate the regimental specific musculoskeletal injury patterns and training outcomes.

Methods: This was a descriptive retrospective observational study of 4101 MSKI reported from a total of 10498 British infantry recruits over four consecutive training years ( $1^{\text {st }}$ April 2012-31 $1^{\text {st }}$ March 2016 at ITC). The cohort comprised of recruits from the parachute regiment $(n=1592)$, Line infantry $(n=6569)$, Guards $(n=1614)$ and the Gurkha regiment $(n=$ 723). Injury data was collected and reviewed for recruit trainees, undertaking the Combat Infantryman Course (CIC).

Results: The four year accumulative incidence varied between the individual training regiments; $66.21 \%(95 \% \mathrm{Cl}$ : 64.19-68.23), 38.48\% (95\% Cl: 35.04-41.92) 34.22\% (95\% Cl: $33.23-35.21)$, and $24.62 \%$ (95\% Cl: 22.76-26.48) for Parachute, Guards, Line, and Gurkha respectively. Overuse MSKI were the most common across all regiments whilst specifically injuries to the knee were most frequently reported with the exception of the Parachute Regiment in which injuries to the calf and shin had the highest reported occurrence. The results show a significant difference $(p<0.02)$ in the incidence of all MSKI between phase 1 and phase 2 training for all training regiments. $45.5 \%$ of the total MSKI reported by all infantry recruits presented within the first 8 weeks of Phase 1 training.
\end{abstract}

\begin{abstract}
Irrespective of injury rate, training outcomes were found to be significantly difference $(p<0.01)$ between regiments. In ascending order, the percentage of regimental recruits successfully completing training at the first attempt was $38.63 \%, 53.78 \%, 64.47 \%$ and $98.76 \%$ for the Parachute, Guards, Line and Gurkha Regiment respectively.

Conclusions: The disparity between MSKI incidence and training outcomes across the Infantry Regiments, suggests that there is a requirement to thoroughly investigate the specific content and delivery of training between the individual regiments.
\end{abstract}

\section{Key Messages}

MSKI are a recognised by-product of arduous military training.

The aim of contributing to a cumulatively growing body of injury surveillance data, specific to individual training regiments within British infantry recruit population.

This paper serves to describe the rate and characteristics of MSK injuries within the different training regiments at ITC in order to direct organisational efforts to reduce MSKI and to mitigate the far reaching implications.

\section{Introduction}

The British Infantry Training Centre (ITC) Catterick, a sub-division of the School of Infantry (SCHINF), is a combined Phase 1 and Phase 2 training establishment. The primary purpose of the Centre is to deliver the Combat Infantryman's Course (CIC) over a minimum of twenty six weeks to up to 4,000 recruits per year [1].

Citation: Heagerty RDH, Sharma J, Clayton J (2017) Musculoskeletal Injuries in British Army Recruits: A Retrospective Study of Incidence and Training Outcome in Different Infantry Regiments. Int J Sports Exerc Med 3:071. doi.org/10.23937/2469-5718/1510071

Received: July 08, 2017; Accepted: September 09, 2017; Published: September 11, 2017

Copyright: (C) 2017 Heagerty RDH, et al. This is an open-access article distributed under the terms of the Creative Commons Attribution License, which permits unrestricted use, distribution, and reproduction in any medium, provided the original author and source are credited. 
Considered the most physically challenging of all initial entry British military courses, recruits are allocated to one of eight training companies under the command of two Infantry Training Battalions. The First Infantry Training Battalion (1ITB) consists of five standard (Line) Infantry regiment whilst the second, Infantry Training Battalion (2ITB) consists of Guards, Parachute Regiment and Ghurkha Regiments. The syllabus is a blend of generic military preparation and regimental specific soldiering skills. Notably, the Guards Company has a specific focus on foot drill and the Parachute Company focuses on the arduous parachute selection course, "P Company" [1-3]. Gurkha training, lasting thirty-nine weeks, is the longest due to its incorporation of three additional packages. These are language, cultural education and tactical close combat and martial arts training. Ultimately, the intent for all training teams is to train young civilians into Class Three Infanteer's suitably prepared to join the British Field Army.

The planning, resourcing and administrative coordination across ITC is the responsibility of the Support Battalion whilst the physical training component is delivered by All Arms Physical Training Instructors (AAPTI) under the management and supervision of the Royal Army Physical Training Corps (RAPTC). Medical support is led by officers of the Royal Army Medical Corps (RAMC) and delivered within the governance of Defence Primary Healthcare (DPHC).

The Army Recruitment Training Division (ARTD) is responsible for the delivery of the training outputs of ITC and these are subject to external military inspection by the Inspector General whilst the educational content, pastoral and welfare provision is assessed every two years by the Office for Standards in Education, Children's Services and Skills (OFSTED). Likewise, Medical management is subject to biennial Healthcare Governance Inspections.

Accurate collection of injury surveillance data is fundamental to meaningful analysis, refinement of clinical service delivery and indicative of a commitment to healthcare governance. The commitment to on-going service evaluation and quality improvement is an imperative reflected in the Infantry Training Centres ' Mission Statement (SCHINF Mission statement ITC Catterick, Battalion Directive 2015-2016).

MSKI are recognised globally as a significant challenge to the efficiency of military organisations $[1,4]$. The British military is not excluded from this observation $[1,5]$. These injuries are identified as having negative impact on injury rates, training time, resources and manning [1,3,6-10].

The increased strain on the medical chain, loss of days in training due to temporary downgrade, placement on light duties and potential risk of subsequent medical discharge presents an on-going challenge to organisational effectiveness. The associated wastage contributes to compromised operational capability and presents a significant financial consideration $[1,3,4,11-15]$.
Consequently, they are considered as a threat to the effectiveness and productivity of the ITC and have potential impact on the supply of trained personnel to the wider British Army $[1,13]$.

Potentially career and therefore life changing events, in the physical domain but seen more increasingly form a psychological perspective; MSKI can have significant impact on the individuals affected. Although the global appetite to identify effective injury prevention strategies is strong, population specific epidemiological data is limited $[1,3,16]$. Accumulating accurate and meaningful injury data is a prerequisite for identifying injury patterns and determining the direction of subsequent interventions $[3,4,14,15]$.

In the transition from civilian to combat-ready soldier, British infantry recruits undergo a minimum of 26 weeks of intense military training. For many, this abrupt increase in physical activity is widely believed to contribute to the subsequent development of MSKI $[1,9,14,15,17,18]$.

While it is clear that MSK injuries are detrimental to the British Army $[1,5,13,14,18,19]$, it is not clear what constitutes an effective management strategy $[3,20]$. A wide variety of demographical injury data has been published. For example, incidences of MSK injuries acquired during military training are reported ranging from $20 \%$ [10], 47\% [21], 48\% [1], 59\% [5], to 59.7\% [6] depending on location.

The "sequence of prevention of injuries" model $[3,22]$ is a popular approach to the management of MSK injuries. The cycle involves four vital steps which include the introduction and evaluation of specific measures designed to prevent MSK injury. The first step in the cycle, and a necessary precursor to any intervention, is to identify and then quantify the problem. Such baseline measures are fundamental in order to assess the success of any given intervention, but particularly important in large institutes such as the military. In such institutes, budgets are determined by policy-makers who require evidence as to the scale of the problem and justify the proportional allocation of resources $[23,24]$. This paper which describes baseline injury statistics therefore represents the first stage in the application of the sequence of prevention injuries model.

Reliable information regarding injury patterns, specifically in terms of injury site (anatomical body area), diagnosis, cumulative incidence, time of incidence (i.e., week of training) and training cohort is particularly valuable when reviewing activity within military training establishments.

An initial paper describing MSKI patterns $[2,3]$ at the ITC observed significant disparity in incidence and training outcomes between individual training regiments and therefore concluded the need for effective injury prevention strategies as well as consideration of the impact of regiment specific training requirements. 


\section{Aim}

This paper, serves to present a four year retrospective regimental specific MSKI trend analysis of the incidence and sub-classifications of 4101 separate MSKI episodes referred to the primary care rehabilitation (physiotherapy) services from a total recruit inflow of 10498 distributed across four training regiments over four consecutive training years. It is intended that this paper will describe baseline data from which the second and third stages in the "sequence of prevention of injuries model" may be applied in Project OMEGA.

\section{Method}

A retrospective observational study design was used to investigate the inter-regimental injury patterns at ITC for four consecutive training years (2012-2016). One full training year represents the period between $1^{\text {st }} A$ pril and $31^{\text {st }}$ March. The Primary Care Rehabilitation Facility (PCRF) at ITC has maintained a password protected MSKI database and the PCRF Administrator initiates entering all MSKI into the injury database. The physiotherapist management team then divides the data into descriptive categories and complete data entering into database. Each MSKI is presented as a new separate case. Repeat injuries within four weeks of initial presentation are recorded within the original recorded episode of care.

On sustaining an MSKI recruits present to the Medical Centre at which point they are assessed and triaged by Combat Medical Technicians (CMT) before onward referral to duty Medical Officers who determine the re- quirement for physiotherapy. If deemed necessary, the Medical Officer refers the patient to the PCRF where an appointment is offered to a recruit within seventy-two hours.

4101 patients from a total inflow of 10498 recruits presented at the PCRF during the period from $1^{\text {st }}$ April 2012 to $31^{\text {st }}$ March 2016. Each patient who presented with a new MSKI was recorded as a new episode of care and information collected according to the injury register database spread sheet.

Recruits injury data were grouped by regiment in order to analyse inter-regimental injury patterns. All recruits, irrespective of training regiment underwent a minimum of 26 weeks military training in order to complete the Combat Infantryman's Course (CIC). The CIC incorporates a combined phase 1 and phase 2 infantry training syllabus, preparing the successful recruits for enrolment into the Field Army.

No further patient demographic information was available. Prior to commencing the $\mathrm{CIC}$ all recruits complete an occupational specific initial service medical health clearance conducted by a General Medical Practitioner. All recruits are required to declare previous illness and MSKI prior to being confirmed as injury free and suitably fit to commence infantry training.

\section{Data Analysis}

Data were extracted from the Departmental MSKI database and analysed for four consecutive training years from $1^{\text {st }}$ April 2012 to $31^{\text {st }}$ March 2016 by the de-

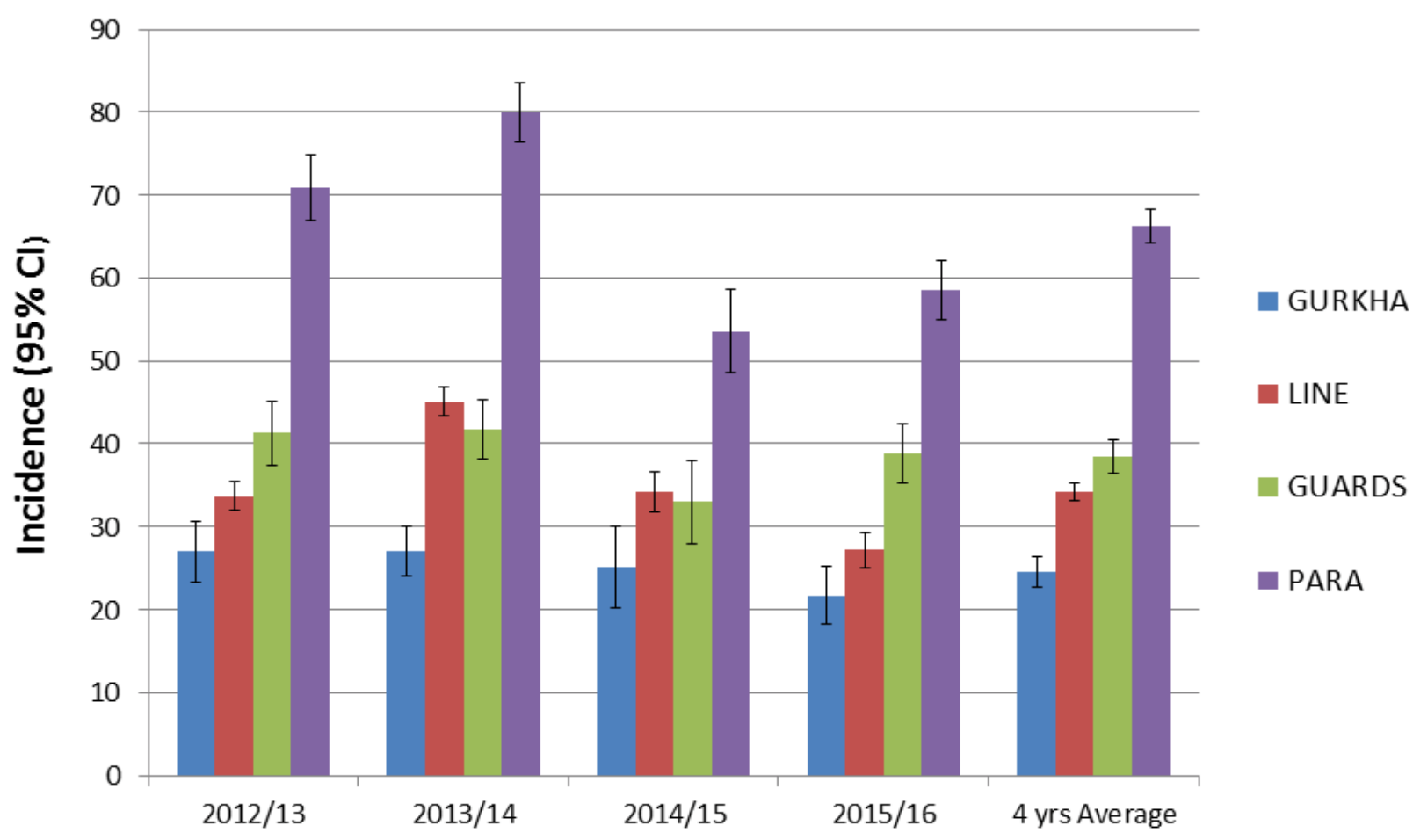

Training Year

Figure 1: MSK injury incidence with $95 \% \mathrm{Cl}$ for each infantry regiments during initial training. 
partmental clinical management team. Injury incidence proportion was calculated as: Injury incidence (\%) = number of recruits with one or more injuries $\div$ total number of recruits in each regiment entering training each year $\times 100$.

All data was checked independently by the departmental Administrator as well as three members of the physiotherapy management team. The baseline data of total number of recruit inflow for each regiment were retrieved from the Training, Administration and Financial Management Information System (TAFMIS) and were cross referenced and confirmed as accurate with those recruit intake figures recorded by ITC G7 Training Cell. Participants' data were then divided into 4 regimental groups. Descriptive analyses with a $95 \%$ confidence interval as well as relative risk were calculated to report differences between regimental MSK injury pattern and training outcome. The Relative Risk (RR), its standard error and $95 \%$ confidence interval are calculated according to Altman [25]. Statistical analyses were conducted using the Statistical Package for Social Sciences (SPSS) software v22 (IBM corporation, USA), with alpha set apriori at 0.05 .

\section{Results}

The four year total inflow of 10498 recruits, was distributed between the four CIC regiments; Gurkha ( $\mathrm{n}=$ 723 or $6.88 \%$ ), Guards ( $n=1614$ or $15.37 \%)$, Para $(n=$ 1592 or $15.16 \%)$ and Line ( $n=6569$ or $62.57 \%)$. The annual total cumulative incidence of MSKI (with a 95\% Cl) for the four separate regiments fluctuates year on year for all four regiment (Figure 1). The four year average incidence rate of injury were; Gurkha $24.62 \%(95 \% \mathrm{Cl}$ : 22.76-26.48), Guards $38.48 \%$ (95\% Cl: 35.04-41.92), Line $34.22 \%$ (95\% Cl: 33.23-35.21) and parachute regiment $66.21 \%$ (95\% Cl: 64.19-68.23). Notably, the relative risk of sustaining an MSKI compared to the Gurkha regiment was, 2.69 (95\% Cl: 2.36-3.07) times more likely for the Parachute regiment, 1.39 (95\% Cl: 1.22-1.59) times more likely for Line and $1.56(95 \% \mathrm{Cl}: 1.36-1.80)$ more likely for the Guards (Table 1).

Figure 2 presents the proportion of recruits who sustained MSKI at specific weeks of training. The gradient and peak of the line indicating the time and incidence of MSKI, thereby illustrating peaks in injury presentation which in turn suggest periods of greater injury risk to the recruits.

Table 1: Musculoskeletal injury, Relative Risk (RR) and 95\% Confidence Interval $(\mathrm{Cl})$ between Regiments during $\mathrm{CIC}$ training 2012-2016.

\begin{tabular}{|l|l|l|l|l|l|}
\hline & RR & 95\% Cl & Sig & NNT (Harm) & 95\% Cl (Harm) \\
\hline Gurkha & 1 (Ref) & & & & \\
\hline Line & 1.39 & $1.22-1.59$ & $\mathrm{P}<0.0001$ & 10.42 & $16.67-7.57$ \\
\hline Guards & 1.56 & $1.36-1.80$ & $\mathrm{P}<0.0001$ & 7.22 & $10.27-5.56$ \\
\hline Para & 2.69 & $2.36-3.07$ & $\mathrm{P}<0.0001$ & 2.41 & $2.664-2.191$ \\
\hline
\end{tabular}

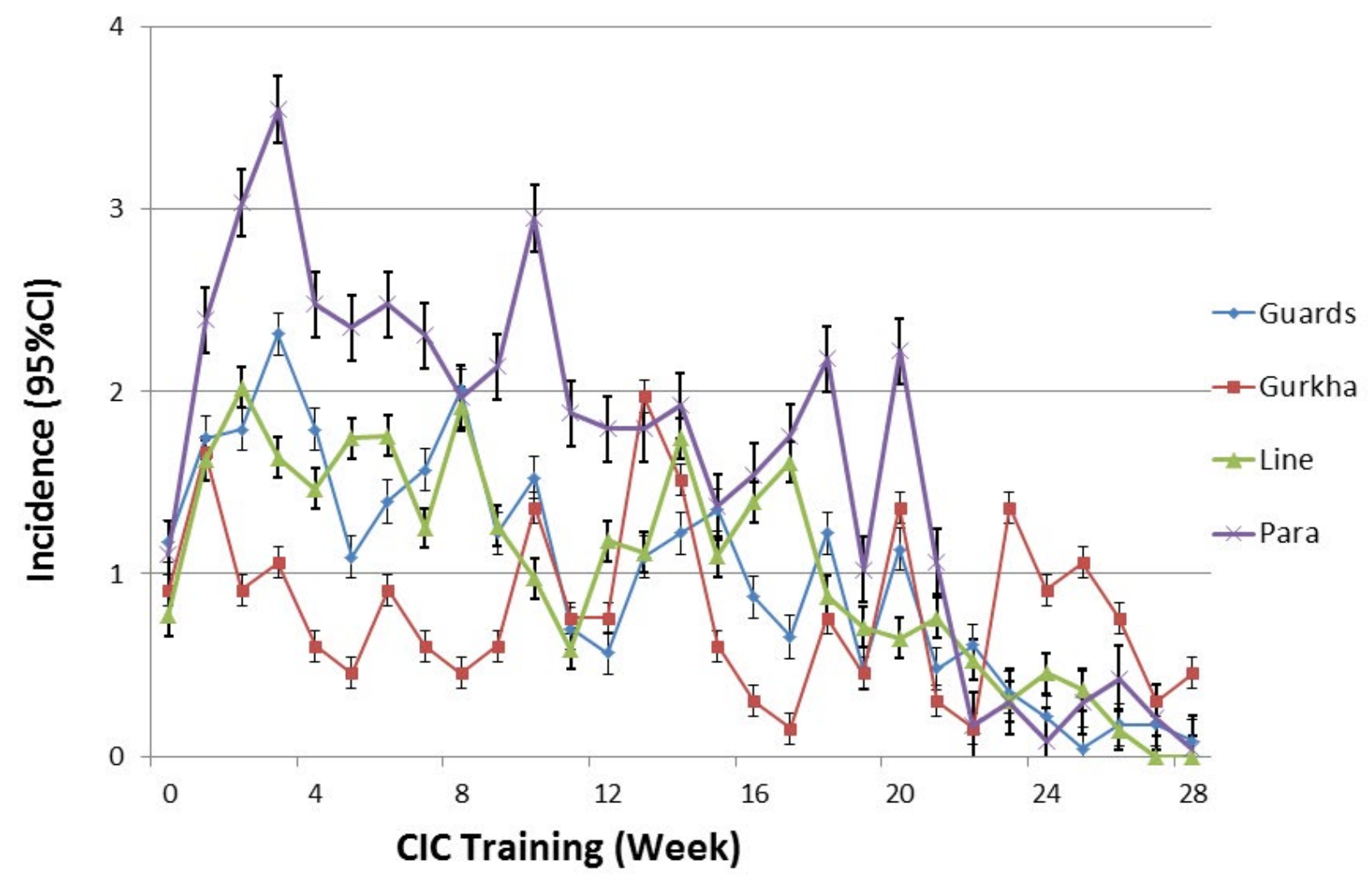

Figure 2: Incidence of injury encountered expressed in percentage with $95 \% \mathrm{Cl}$ at each week during training among four regiments. 
Among the MSKI presented to physiotherapy Department, $45.50 \%$ of all MSKI were reported within the first 8 weeks of training and $77.2 \%$ by week sixteen for all regiments with the exception of the Gurkha regiment. Specifically, the point in training at which the highest incidence of injuries was reported for each regiment were; week 3 for Parachute (3.55\% or $7.57 \%$ among the injury) and Guards (2.31\%) week 2 for Line regiment (2.02\%) and week 13 for Gurkha (1.97\%) (Figure 2).
The most common type of injury for all regiments was overuse, followed by traumatic and then stress fractures (Figure 3). These injuries, alone, have a significant impact on both the recruit and organisational effectiveness. Considered as a four year average percentage of the total recruit inflow for each of the respective training regiments, significant differences $(P<0.01)$ were observed between the incidences of different injury types across all regiments (Figure 3). The pathophysiology of both stress fracture and MTSS dictates that they may

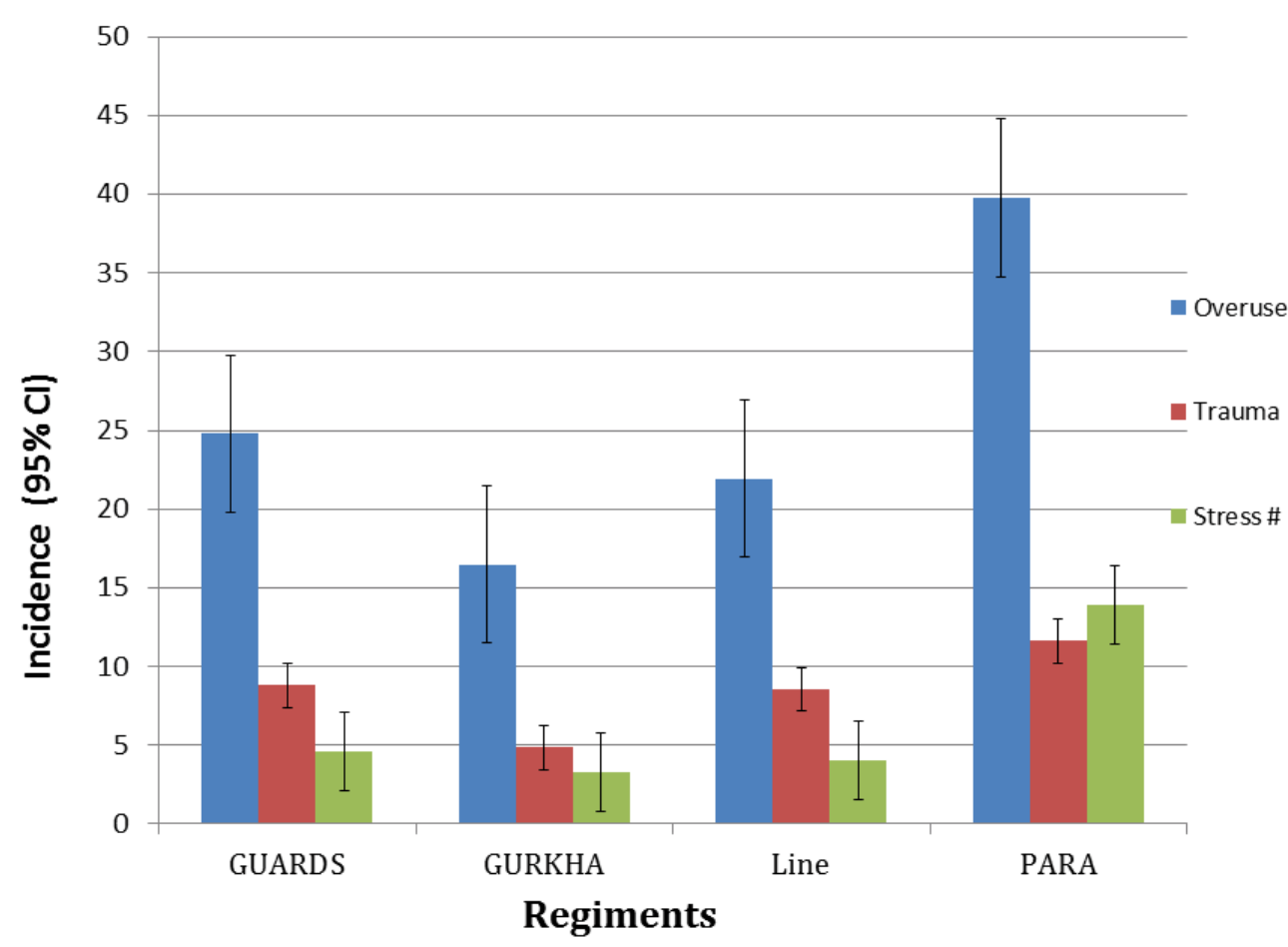

Figure 3: Incidence of injury type for each regiment expressed as a $\%$ with $95 \% \mathrm{Cl}$ of the total MSKI reported from four consecutive training years.
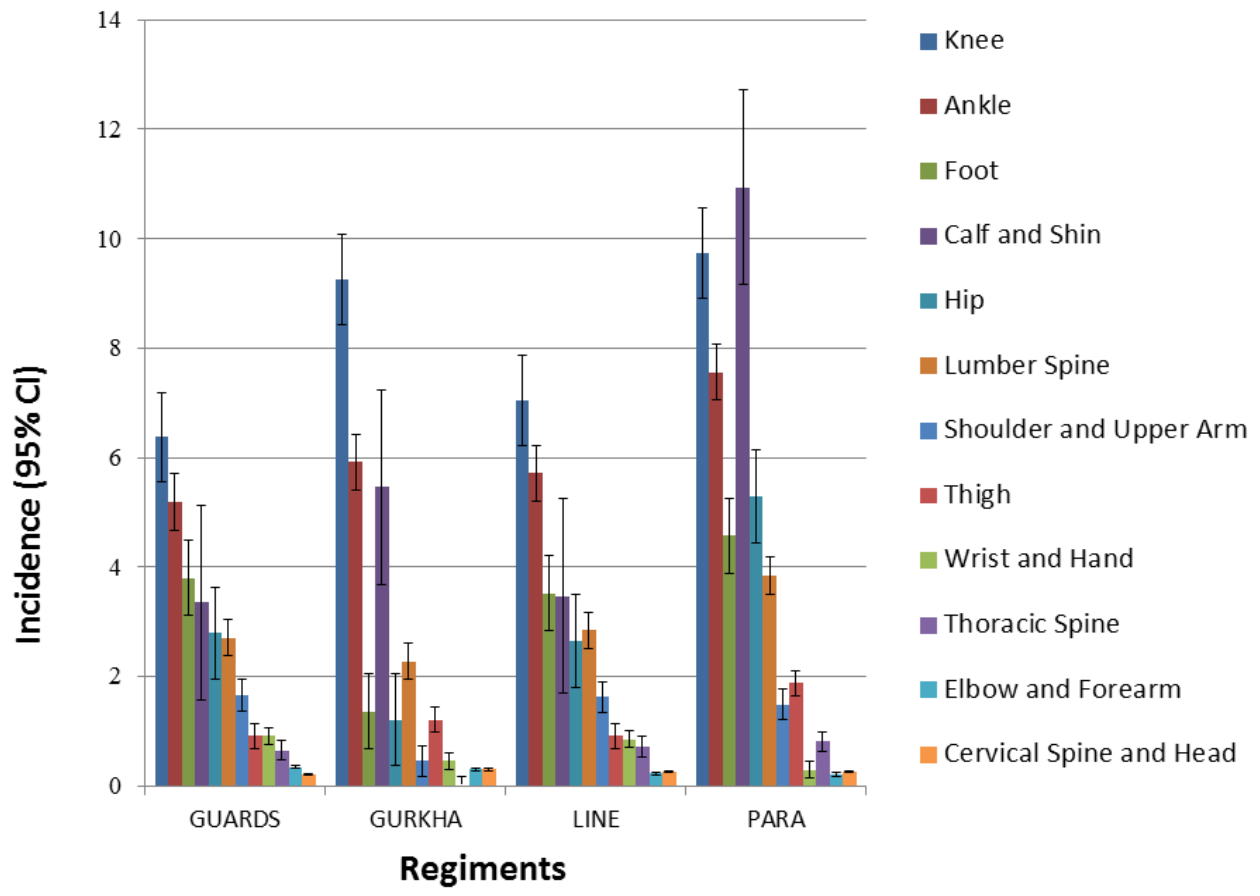

- Cervical Spine and Head regiments. 
also be considered as a sub-classification of overuse injury. Average overuse MSKI for all regiments accounted for $80.34 \%$ of all injuries.

Figure 4 presents a four year average incidence (with $95 \% \mathrm{Cl}$ ) of MSKI according to anatomical location. The parachute regiment had the highest recorded incidence of injuries reported at the calf and shin $(10.94 \%)$ followed by knee $(9.74 \%)$. Conversely, injuries to the knee were the most frequently observed for Guards (6.37\%), Line $(7.04 \%)$ and Gurkha recruits $(9.26 \%)$ with the second most common reported at the ankle for Guards (5.19\%), Line (5.72\%) and Gurkha (5.92\%).

Training outcome, when described as the number of recruits successfully completing both phase $1 \&$ phase 2 on the first attempt, was observed to vary year on year. The average pass out rate taken over the four consecutive years, for recruits completing training at the first attempt differed between regiments; 98.76\% (Gurkha), 64.47\% (Line), 53.78\% (Guards), and 38.63\% (Para) (Figure 5).

\section{Discussion}

\section{Incidence rate}

The overall four year average for regimental specific MSKI incidence rates ranged from 21.67 to $66.21 \%$. The Parachute Regiment displayed both the highest incidence of injury (66.21\%) and the lowest training outcome $(38.63 \%)$ compared to a $98.76 \%$ first time pass out rate for Gurkha. The incidence of all MSKI across all CIC regiments is comparable to the ranges previously reported for other military training populations $(20 \%$ to $60 \%)(8-10)$, as well as those published for civilian run- ning populations ( 25 to $65 \%$ ) [26] but are considerably lower than those reported for professional dancers 67 to $95 \%$ [27]. The Gurkha regiment reports the lowest four year average injury rate $(21.67 \%)$ whilst the Parachute Regiment reports the highest (66.21\%). A Study by Sharma, et al. [1] Previously reported an overall injury incidence of $48.6 \%$ in all British infantry recruits based on 2006-2008 data, whilst another study [5] in the same institution, based on 2009-2011 data, found an even higher injury incidence of $58 \%$. However, although revealing, these studies did not investigate individual regimental specific injury incidence. Sharma and colleagues $[2,3]$, the only previous review of $\mathrm{CIC}$ regimental injury incidence (JRAMC accepted for publication) described rate of incidence ranging from $10-86 \%$.

Although, this study observed annual variation, the four years average injury rate was found to be lower for all regiments, except for Gurkha, when compared to the data collected between 2006-2008 [3]. The reduction of injury may be attributed to a combination of factors, notably, the introduction of new military footwear and/ or the reduction of unnecessary ("Junk") marching. The latter representing the basis for a targeted injury prevention initiative by the Parachute regiment. Notably, Para training which incorporates the arduous "P Company" selection, demands recruits complete greater mileage at a faster pace than the other infantry regiments. It may be postulated that the increased mileage, alone, may contribute significantly to a higher injury incidence in parachute regiment [1-3]. Injury incidence for the Gurkha regiment was found to have increased significantly from $2006-2008(10 \%)$ to the four year average

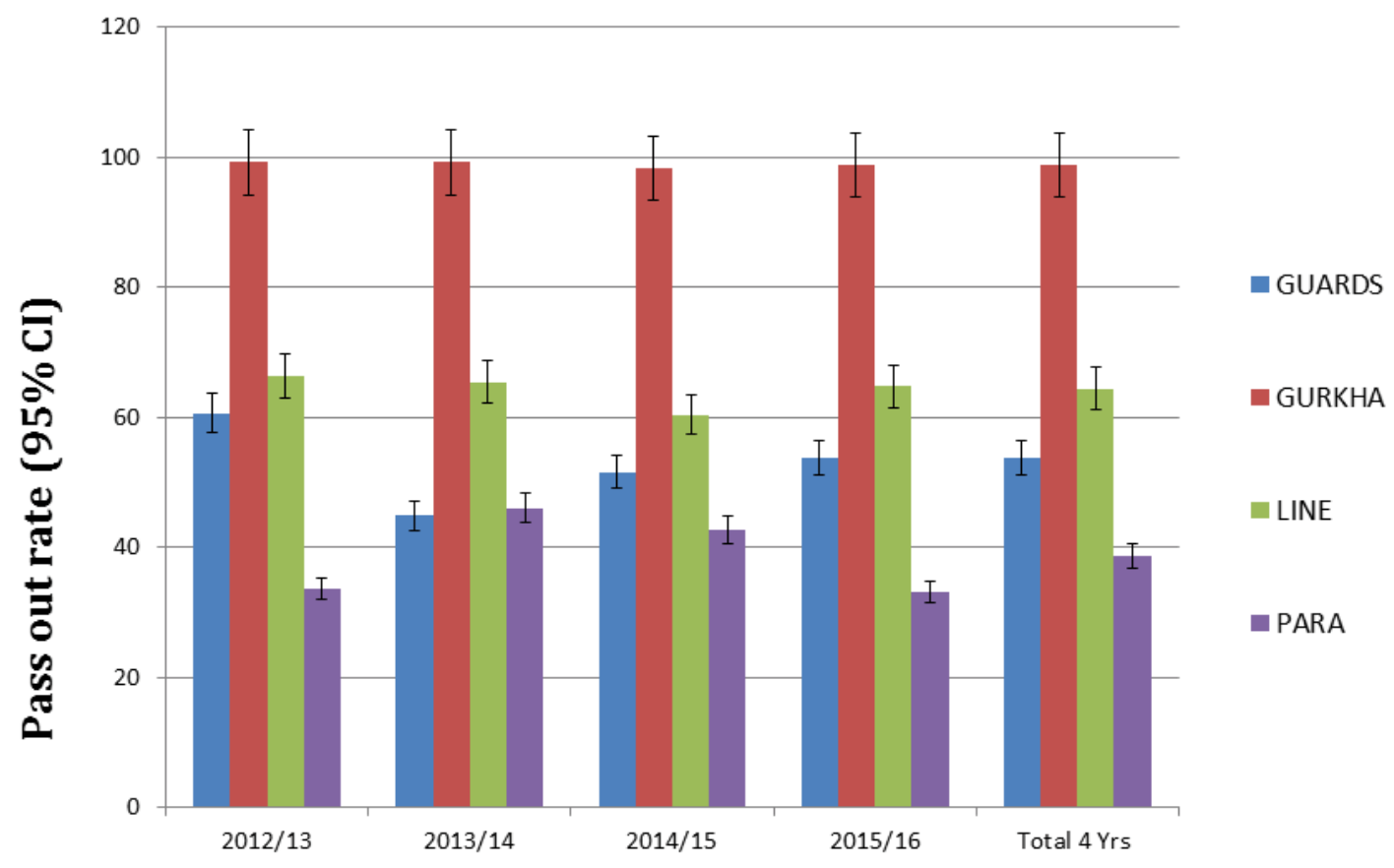

Training Year

Figure 5: First attempt pass out rate with $95 \% \mathrm{Cl}$ for each regiments during initial training. 
of $21.67 \%$ recorded from the $2012-2016$ data. Differences Company" selection in injury incidence between the Regiments may possibly be explained by a combination of the individual regimental selection processes, the pre-existing physical profile of the recruit, the content and delivery of the training programme and or the willingness of recruits to report injury [2,9,28-30]. Indeed it is well recognised that psychosocial factors may also influence recruits decision not to seek medical advice for the management of MSKI [30]. The lower incidence in CIC Gurkha in previous data might be due to under reporting of injury whilst the observed increase (21.67\%) may represent a response to existing health promotion initiatives which actively encouraged the timely and open reporting of MSK from the military population. In the interest of consistency, and to facilitate future comparison the method and analysis of data applied in this study was comparable to that previously applied by Sharma, et al. [2,3].

The risk of sustaining an MSKI was greater for the Parachute, Guards and Line than for the Gurkha Regiment. CIC Parachute regiment included specific P-Company training which involved extra fitness training specifically, running and loaded marches (20 miles) [3,14]. Inter-regimental cultural differences may be considered to contribute to injury variation. Gurkha training was interspersed every 8 weeks for the delivery of language courses lasting 2-3 weeks. These courses provide opportunity for recovery, facilitating the healing rate of overloaded structures, and supporting the physiological training effect [29]. These periods of recovery are therefore likely to positively contribute to the Gurkha recruits tolerance of high impact loading without incurring structural failure. It is widely reported in the literature that overuse musculoskeletal training injuries often result from an abrupt increase in both volume and intensity of physical activity along with inadequate provision of time for appropriate recovery. This is an identifiable training error $[3,9,15]$. Equally, a combination of prolonged high load physical training, mental stress, working in unfamiliar or challenging environments and insufficient recovery may also contribute to the development of potentially reducible MSK injury $[1,11,15,29]$.

\section{Injury training week}

Notably, high rates of injury were observed in the early weeks of the training programme. $45.5 \%$ of injury were presented first 8 weeks of training. Specifically, weeks 2-3 for Parachute, Guards and line regiment and week 13 for the Gurkha Regiment. These findings are similar to those of previous studies which go on to identify the initial weeks of training as a key area in terms of injury prevention $[1,5,9,11,15]$. $54 \%$ of all musculoskeletal injuries have been reported in the first six weeks of recruit training in British infantry recruits [5] whilst an earlier study by Sharma, et al. [1,3] found significantly higher injury rates in the first 9 weeks of train- ing in the British infantry recruits. Possible explanations for the early prevalence may include, a lack of previous exposure to progressively robust physical activity, poor physical fitness, ability to cope with mental stress and working in an unfamiliar environment $[3,11,12,21,29]$. The mismatch of capacity with applied load (combined physical and psychological stress) applied to recruit in a new unfamiliar environment is most likely responsible to contribute to the high incidence of injuries in these early weeks $[1,29]$. There are potential strategies that might be adopted to manage these stresses more effectively, which may be useful when planning an injury prevention programme $[1,3,15]$. First, correcting a mismatch between training load and the ability of the recruit to cope with the stresses. It may be possible to reduce the sudden and abrupt load exerted on the recruits while the musculoskeletal system is afforded opportunity to adapt to a new intensive physical regime through the integrated delivery of neuromuscular strengthening/control and gait education [1,31]. However, this process of positive adaptation requires time. A previous review of the physical demands of $\mathrm{CIC}$ for the Guards regiment at ITC found that the physical demand were greatest in the first 9 weeks of training within which the highest degree of physiological stress was observed in week 2 . Furthermore, the average physical activity levels were 2.5 times the basal metabolic rate which is the upper limit for maintaining energy balance $[1,3,32,33]$. Notably, $60 \%$ of the recruits who failed to pass out from training were, from this cohort, were found to be exercising above this threshold in week 1-2 [1,3,32]. In such cases, the sudden increase in training levels may overload musculoskeletal tissue tolerance and thus lead to the development of structural overload, failure and injury.

\section{Injury type}

The observed regimental injury pattern in terms of onset and anatomical location is similar to previous investigations within both military $[1,5,7,9]$ and sporting populations [34]. Overuse injury is the most common for all $\mathrm{CIC}$ regiments, a characteristic observed in numerous other studies $[1,5,8,9,15]$. However, regimental specific injury data, including type and anatomical location, has been lacking in previous studies. To the best of the author's knowledge, this is the first study to examine regimental specific injury incidence based on anatomical location in the British infantry recruit population.

Lower limb MSKI have been most frequently reported [1,5-10]. Heir, et al. [8] Found $63 \%$ of injuries were sited on the lower limb, similarly Robinson, et al. [5] found $81 \%$ of MSKI reported by British Infantry recruits to be located in the lower limb whilst Almeida, et al. [9] reported a slightly higher rate, $82 \%$, in American recruits. In contrast to the observations of Almeida, et al. [9] Who reported the majority of injuries to the ankle/ foot region followed by the knee, this study found the highest injury occurred at the knee for CIC Guards, Gur- 
kha and Line, with the ankle as second most prevalent site for all. The parachute regiment, however, most frequently reported injuries to the shin and calf followed then by the knee. The findings from this study are comparable to those reported elsewhere in the literature $[1,15]$.

\section{Training outcome/Attrition rate}

The first time pass out rates were seen to fluctuate annually with the four year average ranging from $38.63 \%$ to $98.74 \%$ across all $\mathrm{CIC}$ training regiments. Comparable with a previous study conducted by Sharma, et al. [2,3], the initial pass out rate was observed to vary between the regiments: Gurkha (98.76\%), 53.78\% for Guards and $64.47 \%$ for Line regiments. However, the initial pass out rate for the Parachute regiment was significantly lower (38.63\%) than the other training regiments but observed to be slightly higher than previously published data for this regiment $(35 \%)[35,36]$ and $38 \%[2,3]$. These findings suggest a mismatch between the capacity of the musculoskeletal system and the demands of training. Attrition rates are, in part, a response to recruits failing to adapt to the arduous nature of the cumulative physical and psychological demands of training under a new working environment [37]. However, some of the wastage may be reducible/avoidable if factors such as smarter selection, evidence based training programmes, evidence based injury prevention and treatment are considered $[4,23]$. These factors, if applied correctly, have potential to reduce injury rates, improve pass out rate and reduce attrition [1,3]. Consideration of these factors has been fundamental to the strategic introduction of an integrated injury prevention and physical performance program - Project OMEGA. The results of which are yet to be published.

\section{Strengths and Limitations}

Strength of this study is the large sample size and the period, four years, over which the data were collected. In addition, the observed cohort trained in a relatively controlled environment, wearing similar footwear whilst subjected to an externally validated training programme. This in itself, provides a degree of control over potentially variable extrinsic risk factors $[3,11]$. In addition, the co-located medical facility within the ITC provided injured recruits with timely access to medical care where diagnoses of the reported MSKI were made by occupationally experienced clinicians. However, limitations to this study are identified. A health economics analysis was not conducted as part of this study. Notably, the impact of injury on lost training days, medical support costs, and reduction in operational readiness has not been investigated. However, it is reasonable to suggest that the medical costs of MSK injury management along with the associated loss of time in training, and wastage due to medical discharge may be considered the financial impact [1]. In addition, our samples are all male and homogeneous in terms of recruit characteristics and the content of the training programme. Due to the applied retrospective study design, recruits anthropometrical data and training load were not available on the database and unable to access via medical records retrospectively due to the ethical and Caldicott guideline restriction. It was therefore not possible to analyse and quantify the relationship between anthropometrical data, training load and injury incidence. More detailed information of risk factors, training load and incidence of injury might have helped provide data to reveal established causal relationship with injury incidence.

\section{Conclusions}

MSKI are recognised to represent a significant socio-economic burden inmilitary and athletic population global. This regimental specific study highlights the incidence and variance of MSK injury along with the associated attrition over four consecutive training years at ITC Catterick. Variance in recorded injury patterns between individual training regiments is noted. The impact on wastage, training efficiency, budgetary costs and ultimately operational effectiveness justifies an in-depth review of injury data, training content and exploring opportunities for effective intervention. It is recommended that the British Army continues to invest resources in to the development of effective injury prevention strategies.

\section{Acknowledgements}

The authors wish to acknowledge the considerable support and assistance provided by Col. Byers L/RAMC, Col. S. Dalal L/RAMC, Lt Col. P. Tingey LANCS, Lt. Col T. Booker RAMC and Mrs S. Mclaren as well as the staff of the ITC Medical Centre and PCRF.

\section{Competing Interest}

The authors declare that they have no competing interest.

\section{Authors Contributions}

$\mathrm{RH}$ and JS contributed equally to this work. $\mathrm{RH}$ and JS conceived the study, analysed and interpreted data, drafted and critically review the manuscript and JC involved in the data collection and proof read the final version of the manuscript.

\section{References}

1. Sharma J, Greeves JP, Byers M, Bennett AN, Spears IR (2015) Musculoskeletal injuries in British Army recruits: a prospective study of diagnosis-specific incidence and rehabilitation times. BMC Musculoskelet Disorders 16: 106.

2. Sharma J, Dixon J, Dalal S, Heagety R, Spears I (2017) Musculoskeletal injuries in British Army recruits: a prospective study of incidence in different Infantry regiments. $R$ Army Med J.

3. Sharma J (2013) The development and evaluation of a management plan for musculoskeletal injuries in British army recruits: A series of exploratory trials on medial tibial stress syndrome. Teesside University. 
4. Jones BH, Canham-Chervak M, Sleet DA (2010) An evidence-based public health approach to injury priorities and prevention recommendations for the u.s. Military. Am J Prev Med 38: S1-S10.

5. Robinson M, Siddall A, Bilzon J, Thompson D, Greeves J, et al. (2016) Low fitness, low body mass and prior injury predict injury risk during military recruit training: a prospective cohort study in the British Army. BMJ Open Sport Exerc Med 2: e000100.

6. Linenger JM, West LA (1992) Epidemiology of soft-tissue/ musculoskeletal injury among U.S. Marine recruits undergoing basic training. Mil Med 157: 491-493.

7. Jones BH, Bovee MW, Harris JM 3rd, Cowan DN (1993) Intrinsic risk factors for exercise-related injuries among male and female army trainees. Am J Sports Med 21: 705-710.

8. Heir T, Glomsaker P (1996) Epidemiology of musculoskeletal injuries among Norwegian conscripts undergoing basic military training. Scand J Med Sci Sports 6: 186-191.

9. Almeida SA, Williams KM, Shaffer RA, Brodine SK (1999) Epidemiological patterns of musculoskeletal injuries and physical training. Med Sci Sports Exerc 31: 1176-1182.

10. Franklyn-Miller A, Wilson C, Bilzon J, McCrory P (2011) Foot orthoses in the prevention of injury in initial military training: a randomized controlled trial. Am J Sports Med 39: 30-37.

11. Sharma J, Golby J, Greeves J, Spears IR (2011) Biomechanical and lifestyle risk factors for medial tibia stress syndrome in army recruits: a prospective study. Gait Posture 33: 361-365.

12. Knapik JJ, Sharp MA, Canham-Chervak M, Hauret K, Patton JF, et al. (2001) Risk factors for training-related injuries among men and women in basic combat training. Med Sci Sports Exerc 33: 946-954.

13. Blacker SD, Wilkinson DM, Bilzon JL, Rayson MP (2008) Risk factors for training injuries among British Army recruits. Mil Med 173: 278-286.

14. Wilkinson DM, Blacker SD, Richmond VL, Horner FE, Rayson MP, et al. (2011) Injuries and injury risk factors among British army infantry soldiers during predeployment training. Inj Prev 17: 381-387.

15. Brushøj C, Larsen K, Albrecht-Beste E, Nielsen MB, Løye F, et al. (2008) Prevention of overuse injuries by a concurrent exercise program in subjects exposed to an increase in training load: A randomized controlled trial of 1020 army recruits. Am J Sports Med 36: 663-670.

16. Taanila $H$, Suni J, Pihlajamäki $H$, Mattila VM, Ohrankämmen O, et al. (2010) Aetiology and risk factors of musculoskeletal disorders in physically active conscripts: A follow-up study in the Finnish Defence Forces. BMC Musculoskelet Disord 11: 146.

17. Cowan DN, Jones BH, Frykman PN, Polly DW Jr, Harman EA, et al. (1996) Lower limb morphology and risk of overuse injury among male infantry trainees. Med Sci Sports Exerc 28: 945-952.

18. Wills AK, Ramasamy A, Ewins DJ, Etherington J (2004) Anterior Knee Pain During Army Recruit Training. J R Army Med Corps 264-269.

19. Sharma J (2008) Annual Report 2007 on the health of the army. Camberly.

20. Chalmers DJ (2002) Injury prevention in sport: not yet part of the game? Inj Prev 8: 22-25.
21. Knapik JJ, Graham B, Cobbs J, Thompson D, Steelman R, et al. (2013) A prospective investigation of injury incidence and risk factors among army recruits in combat engineer training. J Occup Med Toxicol 8: 5.

22. van Mechelen W, Hlobil H, Kemper HCG (1992) Incidence, Severity, Aetiology and Prevention of Sports Injuries. Sports Medicine 14: 82-99.

23. Jones BH, Canham-Chervak M, Canada S, Mitchener TA, Moore S (2010) Medical surveillance of injuries in the u.S. Military descriptive epidemiology and recommendations for improvement. Am J Prev Med 38: S42-S60.

24. Finch C (2006) A new framework for research leading to sports injury prevention. J Sci Med Sport 9: 3-9.

25. Altman DG (1991) Practical statistics for medical research. Chapman and Hall, London.

26. Taunton JE, Ryan MB, Clement DB, McKenzie DC, LloydSmith DR, et al. (2003) A prospective study of running injuries: the Vancouver Sun Run "In Training" clinics. Br J Sports Med 37: 239-244.

27. Luke AC, Kinney SA, D'Hemecourt PA, Baum J, Owen M, et al. (2002) Determinants of injuries in young dancers. Med Probl Perform Ar 17: 105-112.

28. Kaufman KR, Brodine S, Shaffer R (2000) Military training-related injuries: Surveillance, research, and prevention. Am J Prev Med 18: 54-63.

29. Meehan HI, Bull SJ, James DV (2002) The role of non-training stress in the development of the overtraining syndrome. J Sports Sci 20: 69-70.

30. Junge A (2000) The influence of psychological factors on sports injuries. Review of the literature. Am J Sports Med 28: S10-S15.

31. Sharma J, Weston M, Batterham AM, Spears IR (2014) Gait retraining and incidence of medial tibial stress syndrome in army recruits. Med Sci Sports Exerc 46: 1684-1692.

32. Carter JM, Izard RM, Blacker SD, Wilkinson DM, Rayson MP, et al. (2006) The physical demands of the combined infantryman's course for foot guards at ITC Catterick. Optimal Performance Limited and ARTD.

33. McGinnis PM (1999) Biomechanics of sport and exercise. Leeds: Champaign IL, Human Kinetics.

34. Gamboa JM, Roberts LA, Maring J, Fergus A (2008) Injury patterns in elite preprofessional ballet dancers and the utility of screening programs to identify risk characteristics. J Orthop Sports Phys Ther 38: 126-136.

35. Franklyn M, Oakes B, Field B, Wells P, Morgan D (2008) Section modulus is the optimum geometric predictor for stress fractures and medial tibial stress syndrome in both male and female athletes. Am J Sports Med 36: 1179-1189.

36. Wilkinson DM, Rayson MP, Bilzon JL (2008) A physical demands analysis of the 24-week British Army Parachute Regiment recruit training syllabus. Ergonomics 51: 649-662.

37. Huovinen J, Tulppo M, Nissilä J, Linnamo V, Häkkinen K, et al. (2009) Relationship between heart rate variability and the serum testosterone-to-cortisol ratio during military service. Eur J Sport Sci 9: 277-284.
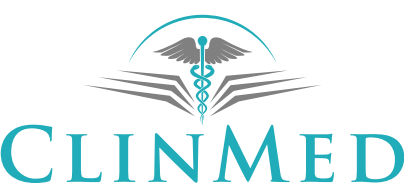

INTERNATIONAL LIBRARY 